\title{
REMARKS ON MENTAL CONTAGION AND INFECTION INHERITED OR ACQUIRED; WITH CONSIDERA- TION OF SOME MEASURES OF PREVENTION OF INSANITY AND DEGENERACY.'
}

By RICHARD DEWEY, M. D., Wauwatosa, $W$ is.

For the purposes of this paper I do not use the words "Contagion" and "Infection" in their usual sense though in a legitimate sense and one recognized by writers of authority. By contagion I here mean psychopathic contagion,- the morbid influence of insane minds upon other minds; and by infection, the diseased process whereby certain of our race are either born so predisposed or defective that normal mental development is impossible, or acquire in later life such predisposition or defect.

Concerning mental contagion there can be no difference of opinion; but objection may be made to the use of the word "infection" in the above connection, and I am not strenuous upon that point, but yet believe it is not transgressing the bounds of truth to state that certain psychopathic individuals are "infected" with insanity. The germs of insanity are in their constitution (using the word "germs" in its wider sense) in some cases, from the hour of birth-nay, from the hour of conception; in others from later acquirement, and will develop as surely as smallpox or typhoid fever will follow the infection of those diseases.

It is literally true that certain mental and nervous diseases are the result of toxins of bacterial or other origin, and that there are specific infections, capable of causing insanity directly or indirectly; the number of these, however, compared with the mass of insanity, is insignificant, and may be left to those better

${ }^{1}$ Read before the American Medico-Psychological Association, May 24, 1899. 
able than I to treat of them technically, while I invite your attention to those more difficult and numerous cases which we can never hope to reach by serum treatment, or any antiseptic, but where the psychical genesis of disease is as real in its working as any bacterial agent; for, not only may insanity be thus conveyed but nervous disorders, like hysteria and chorea, spread from a single sufferer to an indefinite number of others.

In giving some examples of mental contagion, I may speak briefly of those epidemics of madness-not strictly insanitywhich are recorded at various epochs but which were especially rife in the middle ages; which furnish striking examples of mental contagion, whether or not we agree that "the isolated cases of insanity of our age have their counterpart in the epidemics and endemics of the days of old." ' These epidemics were due either to general psychopathologic tendencies of the age in which they occurred or to the fanatical leadership of individuals like Montano, Valerian or Hassam. These epidemics were variously marked: by hallucinations, pure and simple; by religious ecstasy or political or pseudo-scientific delusions, like flagellation or alchemy; or by convulsive manifestations, hysteria, chorea and the dancing manias. To briefly particularize: In the and century appeared the Adamites praying nude and returning as they thought to primitive purity and simplicity. In the 5 th and 6th centuries, the alchemists, carried away by false science (the counterpart of insane inventors of to-day). In the $5^{\text {th }}$ century, in Alexandria, there was an epidemic of barking and howling like a dog, participated in by many men, women and boys. In the 8th century a great epidemic of demonology occurred, beginning in Calabria and Sicily and extending over Greece, Epirus, the Igean Isles and even to Constantinople, in which hallucinations of dark olive-colored crosses were seen upon the clothes of persons affected. These were followed by the appearance of a carbuncle that quickly consumed its victim.

(It is to be noted that the above epidemic, like that of the flagellants in Perugia in the $13^{\text {th }}$ century and like the religious epidemic ecstasy in Sweden in 1841-42, was accompanied by severe somatic disease, that of Perugia being ergotism and in

'Dictionary of Psychological Medicine, p. 434. 
Sweden starvation and poisoning from bad harvests and impure food.)

In the I2th century the "Assassins" appeared under Hassam, "the Old Man of the Mountain," who promised the delights of Paradise to those who obeyed. These did not scruple at selfmurder or homicide, performed with entire indifference and probably in part under the intoxication of opium or hasheesh.

In the I $3^{\text {th }}$ century, the flagellants arose in Perugia and the fanaticism spread throughout Europe, seemingly caused by ergotism among the people in convulsive and gangrenous form.

In the I4th century, the dancing mania and tarantism, or the delusion of being bitten by a scorpion, led to astonishing outbreaks of frenzy, involving many countries and continuing through two centuries.

Time forbids the mention even of all the epidemics and endemics, extending on through the Christian era but becoming far less frequent and involving fewer persons after the revival of learning and science. To-day in milder form and implicating smaller numbers, especially in civilized countries, we see crazes and fads of various sorts, like Mesmerism, Adventism-as shown by the Millerite sect-Spiritism, Christian Science, Osteopathy, Lourdes pilgrimages, etc.; and in savage races, Mahdism, " running amuck," American Indian Messiah dances, etc.; while in a smaller circle epidemics of hysteria and ecstasy have appeared and still appear in boarding-schools, monasteries, etc.; an illustration that may be cited of the latter, being an epidemic a few years since of hysterical mania in a girls' industrial school, a state institution of Illinois, where during Gov. Altgeld's term anarchy appeared and led to general window-smashing, furnitureand crockery-breaking and maniacal frenzy and shrieking throughout the entire establishment for two or three days under the lead of one or two vicious and highly neurotic girls.

As further illustrations of mental contagion in our own day I would add some facts from my own experience. I have known one violently hysterical patient to cause the development of hysteria in a dozen other patients suffering from other maladies in the medical wards of a general hospital. I have seen a patient having the delusion that the end of the world was at hand infect six or seven others suffering from other forms of insanity in 
the wards of an asylum. I have observed a patient affected with delusions of poisoning so influence six or seven of his fellow patients that they too began to refuse food; and this in spite of the well-known fact that the insane are not easily affected by the suggestions of others. I have seen chorea in a girl of fourteen attack a younger sister and produce incipient symptoms in a third child before the children were separated. Similar experiences could doubtless be recalled by many of my hearers.

The effect of one insane member of a family upon the other members and upon neighbors and bystanders, with which we are all familiar, forcibly illustrates mental contagion and infection. Among numerous similar cases, Babcock has reported an interesting one in South Carolina of a whole family requiring to be besieged and captured by the officers of the law, and Burr a somewhat parallel one in Michigan. These astonishing cases, however, only furnish an exaggerated example of what is going on more or less everywhere when an insane person is kept in contact with a family. The extensive and incalculable harm, especially to children, we cannot doubt has a deep and far-reaching influence in spreading insanity and furnishes a tremendous argument in favor of quick separation of the sane and insane instead of the reverse policy which now prevails; not only for the sake of preventing contagion, but for prospect of cure. These facts also furnish a strong argument against the boardingout of the insane as is done in Scotland; at the Gheel colony, Belgium, and attempted in Massachusetts.

Mental contagion in its slower working is illustrated by the folie a deux of the French writers which indeed often includes three or four victims in one house or family, and I have myself in one instance seen five members of one family affected at the same time, three of whom came under my care in one day. Doubtless many of these cases come under the division of those hereditarily predisposed. In this connection may be mentioned the question of development of insanity in those who are brought much in contact with the insane in the capacity of attendants, nurses and physicians.

All who have been long familiar with these matters know that many cases occur where attendants, nurses and to some extent physicians, or members of their families, have developed insanity 
after years of contact with the insane. The number of these cases is such as to be rather striking, yet no statistical figures can be given. I found at one time that five or six cases of insanity had occurred among about as many hundred attendants at the State Hospital at Kankakee-a proportion four or five times as large as that among the general population-yet in most of these cases there was a highly nervous and unstable constitution to begin with, and in these, as in all other cases, where insanity develops, the predisposition plays a most important part, and the insanity was known to be hereditary in some of the cases. On the other hand, we all know cases of those brought in most trying contact with the insane for long periods, who would certainly go insane, if such contact would of itself accomplish the result, who remain mentally sound and robust to the end. We probably underestimate rather than overestimate the power of heredity. I would not go so far as a recent ingenious writer in the London Lancet who, in an article on the "Marriage of the Unfit," maintains that even flea-bites are hereditary, justly claiming that certain persons are quite immune to fleas and that it depends upon a certain inborn and inherited susceptibility or peculiarity of the skin or its nerve supply, whether you suffer or not from an inflamed wheal when bitten by a flea.

The above remarks anticipate in a measure the consideration of mental contagion or infection as accomplished by the less obvious but equally disastrous results of inheritance. The facts of this method of communication of mental and nervous disease are so obvious that I need not dwell upon them. I do not say that in all cases where insanity, nervous disease, epilepsy, suicide, etc., appear in the same family, they are necessarily inherited or communicated; but when the facts clearly established, even with the small means of obtaining them in our public asylums, show that more than 50 per cent of the patients have near relatives insane, we must recognize this factor, and in considering the workings of mental contagion, we must recognize the fact of a predisposition existing; $i$. e., the most of the individuals affected are constitutionally predisposed, and probably would not succumb but for this predisposition,- $a$ fact making it all the more important, where possible, to protect from exposure to contagion.

It may have been noticed that in my title I include "degen- 
eracy" among the effects of contagion and infection, and this may seem an unwarranted assumption. A degenerate individual may or may not be capable of affecting injuriously those about him by ordinary contact; but degeneracy may be and often is conveyed to the offspring of the degenerate in a manner as positive and unerring as when a specific microbe is conveyed to the body of an exposed person and there sets up its diseased process.

In a fanciful but nevertheless true sense the human ovum, or spermatozoid, may be regarded as a microbe of all degenerate diseases, and the act of procreation an act of conveying diseased infection. It is much more than this, truly, but this is an essential part of it, and it cannot be doubted that the propagation of nervous and mental disease by extension from generation to generation is the most serious morbific influence with which we have to contend.

If it now be granted that insanity and degeneracy are conveyed chiefly by mental contagion and infection and by infectious inheritance and also acknowledged (which no one disputes) that these diseases are increasing to a disquieting extent, it is admittedly important to inquire what can be done to counteract these dangerous tendencies. The question of "Mental Sanitation," if I may use the term, presents itself with considerable force; and in this connection I wish to inquire whether we may expect to reach useful results by formulating legislation with a view to prevent the spread of mental contagion and infection, by more strict control of the insane and degenerate, by separating them more thoroughly from the community at large, by regulating marriage, by rendering such persons incapable of reproductive activity through surgical procedures, by judicially ending the days of the hopelessly insane, etc.

A significant remark was recently made to me by a colleague in discussion of the methods of care of the insane in vogue to-day in our country. This colleague animadverted unfavorably upon the extreme care taken of the insane and degenerate in our communities, fostering and protecting them in institutions and prolonging their lives and temporarily curing many who are returned to private life and there secure abundant opportunities for propagating their kind. He expressed the fear that this process 
of spreading mental and nervous disease and degeneracy and promoting their procreation would eventually lead to multiplying these diseases enormously and disastrously from generation to generation and regarded it as a mistaken kindness to render comfortable and agreeable, and thus promote vitality and vigor of, our defectives. This view, which one hears more and more frequently expressed, appears to set at naught all the philanthropy of our day and is indeed "important if true." A juster view, however, it seems to me is that, bad as the conditions of degeneracy are to-day, they are undergoing a favorable modification and are far less mischievous than in former ages. They may indeed be regarded as a mild survival of the frightful mental, physical and moral pestilences, plagues and epidemics, which have raged in former ages.

Also what was formerly regarded as witchcraft and demoniacal possession is seen to-day to have been brain-disease. The innumerable crazes and epidemics of pseudo-religious nature, the convlusive manias, the flagellants, the tarantists or dancing maniacs, the anointers, the poisoners and the alchemists have ceased to rage by the growth of enlightenment and spread of intelligence, perhaps surviving, however, to-day in what all recognize as madness and degeneracy which, bad as they are, are mild compared with the scourges of foregoing ages, and reach smaller numbers. To admit that our condition is growing worse would be to ignore the certain tendency of both mind and body to free themselves from disease under improved conditions; and to admit that our benevolence is a mistake would be to set back the hands upon the dial of progress. We must, however, find remedies for what we all admit is an evil in our times crying aloud for correction.

Now, most of the suggestions of legal remedies are in my opinion crude and impracticable. There are certain fundamental principles upon which the framework of society rests that are contravened by attempts at legislating for certain special conditions; class legislation when applied to persons of various degrees of mental health and sickness is as vicious as any other class legislation and its application in enlightened communities will only be permitted by public opinion where the clearest and most unmistakable lines can be laid down; and in these nervous and 
mental diseases and defects it is at present a matter of impossibility to draw universally satisfactory lines.

We may expect that eventually guiding principles will be established. Laws have been in recent times enacted and enforced regulating and controlling the contagions of diphtheria, smallpox and yellow fever, but these diseases are capable of universal recognition in their origin, diagnosis and treatment and are promptly fatal, while there is yet too much which is obscure and unsettled in nervous and mental diseases, and their slower fatality prevents their equal danger from being as yet appreciated. Mental sanitation is as yet in its infancy, and the diagnosis and treatment of mental and nervous disease must be perfected and definite lines established upon which all are agreed before any measure of legal control can be assumed.

If, for instance, a law were enacted creating an Agency, a Board or Bureau, giving it power to permanently imprison, to electrocute, to castrate, certain insane, imbecile, epileptic, inebriate or degenerate beings; when we endeavor to think out for ourselves the steps by which such a Board would proceed, the means they would use, the details they would find necessary in arriving at any result, we see at once the futility of such legislation.

It may be possible that certain conditions of congenital idiocy or incurable insanity can be so defined as to be made the subjects of legislation, but it is precisely these cases that are the least likely to be mischievous. It is the degenerate or insane or imbecile persons who are close to the normal line and who are at different times, perhaps, on both sides of it, who can be controlled by no law, and yet produce the most evil by their existence in the community.

These evils, like those of prostitution, of venereal disease, of intemperance, are a perpetual scourge to the welfare of our society, and yet defy the utmost ingenuity of the law-making power to control, except where they become amenable to the plainest provisions of the Common Law. This fact should not deter the well-wisher of his kind from all effort, but rather should incite to greater activity, but of a kind calculated to reach more practical results; and in my opinion, the mode in which practical results are to be reached, is by education and spread of enlight- 
ened views, so that both society and individuals can see what is for their common interest. In this matter there is no conflict of interest, for the propagation of insanity and degeneracy is as disastrous to the individual as it is to the community. A citizen of even moderate intelligence who would resist a compulsory law, if brought to see the workings of inheritance, of contagion and infection in mental disease and defect, would in many cases voluntarily avoid the penalties imposed by nature.

The efforts that physicians and scientific men can make to enlighten the public mind, seem to me to be the only present resource. The ignorance of the masses upon these subjects is the chief reason why such deplorable conditions of mental sanitation exist. Sanitation as it relates to physical disease is now coming to be better and better understood and the same work that has been done in bringing this about so that diphtheria and smallpox can be controlled, will require to be done before the people understand the things that pertain to their welfare and peace in relation to insanity and degeneracy. It seems probable, however, that if the time ever arrives when legislation requiring castration, forbidding marriage or providing a peaceful death for incurables can be enacted and enforced, the time will also have arrived when it will not be needed.

The fundamental ideas regulating these matters are that public opinion will tolerate no legislation which risks the oppression of innocent persons; neither will any measure which is harsh or brutal be countenaced, even against the most worthless or imbecile; nor will any law be favored which trifles with human life, even the life of the most useless and degraded. Civilized Christian society holds itself responsible for the protection of all its members. It assumes the humane care and support of all its helpless ones. Therefore, all measures which involve the taking of life, the denial of liberty, must be so hedged about that their operation will involve no mistakes and no injustices. For these reasons the legislation so often advocated which contemplates permanent imprisonment of any one unless convicted of a capital crime or incurably and dangerously insane; which denies the right to marry and to give in marriage of any person because it is probable his offspring will be insane or degenerate; which proposes that any citizen shall submit to a surgical operation 
contrary to his will, must, at present, fail of enactment or if enacted, fail of enforcement. Theoretically, you will hear ten men agree that an imbecile man, woman or child, or one whose family is severely affected with insanity, epilepsy or inebriety, should be denied the right of marriage, or should even be subjected to castration; but let one of the ten be touched in his person or family by such a regulation, he will set it at defiance and the courts would often sustain him in doing so. Those who are ignorant and defective cannot voluntarily agree to such control or restriction, and those who possess a degree of intelligence will proclaim their ability to regulate rightly their own conduct without being made virtuous by "acts of congress." Thus, hitherto the propagation of disease and defect of mind seems to go unimpeded onward and it may be that our race is thereby to become more and more degenerate and incapable; but in taking so dark a view, do we not lose sight of certain saving agencies in the unwritten laws of evolution and devolution?

If we must admit that our benevolence and easy toleration of defective humanity promote in some measure the survival of unfit persons, still this fact may be regarded as an incident in the larger movement which makes for universal health which our day is witnessing. The study and comparison of conditions can but convince the candid mind that these progressively improve; and any evil of our fostering the unfit is a negligible quantity compared with the whole trend of sanitary and hygienic thought and action.

Imbecility, inebriety, insanity, degeneracy tend to extinguish themselves, even without the aid of intelligence and justice, and when we add these factors, ever more powerfully working in the life of men and nations, we have a force which, working in harmony with natural laws, is capable of purifying and elevating the whole fabric of society. We constantly see children of vicious and degenerate parents develop into normal and healthful citizens if separated from evil associations and conditions and placed in a salubrious and sanitary environment.

Finally, I wish to say that in my opinion the measure of first importance and the only one which can practically solve all the difficulties here considered is the oft-repeated and seemingly humdrum one of so providing for all the insane, in amplitude of 
accommodation and excellence of service, that there will be a place for all and that the high character of the care given will overcome the reluctance (still great but far less than in former days) to go or be sent to a hospital for the insane. Objection may be made to the heaping together of masses of the insaneand it undoubtedly has its disadvantages-but it is assuredly the lesser of two evils. At the same time the disadvantages of massing the insane are being patiently and efficiently overcome and rapidly, too, at the present time, by admirable work in all parts of our country. The well-equipped hospital for the acute and curable insane, the separation of the epileptic, the criminal, the alcoholic cases and the deeply demented, together with the remarkably improved classification, remove all valid objections and gladden the hearts of those of us who for these many years have been advocating these measures.

It is, therefore, by education and instruction disseminated earnestly and unceasingly throughout the community that we have our chief means of combating these injurious agencies, and not by attempting to regulate by statutes things which must be

- left to the growth of mental and moral rectitude in the community.

Although civilization seems to breed disease of brain and mind, and although at times we are forced to look upon dark pictures of multiplying degeneracy, crime and decay, and seem to see hideous maladies and defects increasing hopelessly about us; yet if we compare in a large way our state with that of the ages that have gone, if we reflect upon what has been overcome, we have reason to believe that the never-ending, still-beginning campaign of science and education against error and disease will in the end bring about a sane and healthful state of mind in the body politic, and we shall then have in the larger sense for the whole community, mens sana in corpore sano. 